\title{
Effects of probabilistic independent outcomes upon predictions'
}

\author{
FRANCIS W. IRWIN AND MARSHA JOAN METZGER
}

UNIVERSITY OF PENNSYLVANIA

Ss won or lost 10 cents for correct and incorrect predictions of draws from binary packs. The draws also had independent outcome values (10's) that depended upon the cards drawn but not upon the predictions. These 10's were probabilistic, with expected values ranging from 10 cents to -10 cents. Cards with positive 10 were predicted significantly more often than cards with negative 10 , with objective probability constant.

Predictions of uncertain events are affected by event-values that do not depend upon the correctness of the predictions-independent outcome values or IOsas well as by values that are contingent upon the correctness or incorrectness of the predictions-dependent outcome values or DOs. Marks (1951), Morlock \& Hertz (1964), Pruitt \& Hoge (1965), and Irwin \& Snodgrass (1966), among others, found that children and adults were more likely to predict the occurrence of an event if its Io was positive than if it was negative. In all of these studies IO was certain, given the occurrence of the event. The present experiment extends the problem to cases in which IO, as well as the event, is probabilistic.

Subjects

The Ss were 25 male and 25 female undergraduates at the University of Pennsylvania and Temple University. They were recruited with a promise of $\$ 1.00$ for their services.

\section{Procedure}

The Ss were seen individually and were told that they were to play a "decision-making game." On each trial, $S$ was required to draw one card from a shuffled pack of 10 cards, of which $1,3,5,7$, or 9 were marked with a large $X$ printed in bold-face ("marked" cards) and the remainder were blank. The drawn card was kept face down. $S$ then drew one card from a pack of 10 cards of which $0,1,3,5,7,9$, or 10 had a " $10 "$ printed on the face in large bold-face type and the remainder had a " $-10 "$ " in the same style. This card also was kept face down. Before drawing from either pack $S$ predicted whether he would draw a marked or a blank card from the first pack. The information available to him included: the number of marked and blank cards in the first pack; the fact that both packs had been shuffled; the fact that if his prediction was correct he would win 10 cents and if it was incorrect he would lose 10 cents (the DO); and the fact that if he drew a marked card, then his draw from the second pack would count 10 cents or -10 cents, according to the face of the card drawn from that pack, whereas if he drew a blank card from the first pack, the draw from the second pack would not count and would not even be looked at (the IO). Thus, drawing a marked card from the first pack had an expected 10 of -10 , $-8,-4,0,4,8$, or 10 cents depending upon the packs being used, and drawing a blank card from the first pack always had an IO of zero. On each trial, $S$ had before him a typed slip telling him the number of marked and blank cards in the first pack and the number of $10^{\prime} \mathrm{s}$ and -10 's in the second pack; this information was also given orally by $\mathrm{E}$. After the prediction and the two draws, $\mathrm{E}$ recorded the prediction and the cards drawn, but $\mathrm{S}$ was given no feedback until the end of the session. There were 35 trials (five probabilities of drawing a marked card times seven expected values of IO). The drawn cards were placed in their packs at a right angle to the other cards and the packs were returned to a card holder in such a way that $S$ could see that the cards he had drawn could be identified later. At the end of the session, the cards were inspected by $S$ and $E$ and payoffs were made in accordance with the rules that had been stated to $\mathrm{S}$. No $\mathrm{S}$ had a net loss from the procedure.

\section{Results and Discussion}

As in previous experiments, marked cards were predicted more frequently when they had positive IO than when they had negative IO. This was true for both sexes and at both the individual and group levels.

At the level of individuals, a difference score was obtained for each $\mathrm{S}$ by subtracting the number of times he predicted a marked card when marked cards had negative IO from the number when marked cards had positive IO. These difference scores were positive for $35 \mathrm{Ss}$, zero for 7 , and negative for 8 . When the two extreme values of 10 , which involved no uncertainty, were excluded, the corresponding frequencies were 35,6 , and 9 . Both departures from symmetry were significant by the standard error of a proportion, with $\mathrm{p}<.01$.

Figure 1 shows for all Ss as a group the percent of predictions of marked cards as a function of the expected value of $\mathrm{IO}$, with probability of drawing a marked card as parameter. It can be seen that these percents were greater with positive than with negative expected IO. At each probability, the smallest relative frequency on the positive side was larger than the largest relative frequency on the negative side, with a single exception (that for expected IO of 4 cents with probability .1). The mean difference scores were as follows: for all Ss over all IO values, 2.6; for males only,2.2; for females only, 3.0 ; for all Ss over all IO's except tha two extreme values, which involved no uncertainty, 1.5; for males only, 1.0; for females only, 2.0. All of these means 


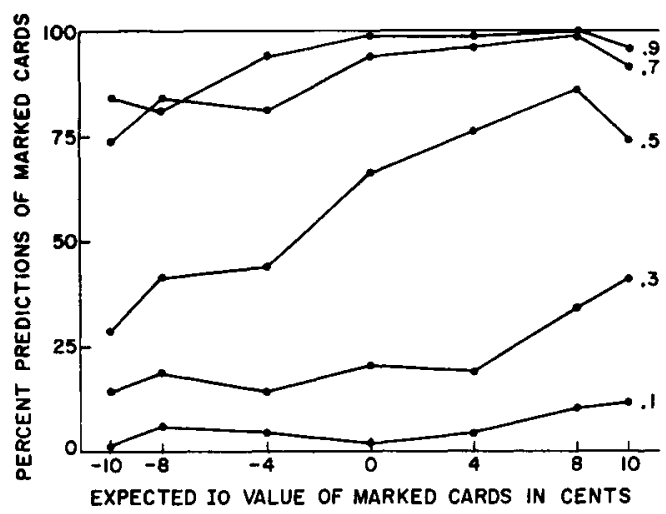

Fig. 1. Percent predictions of marked cards as a function of expected 10 value of marked cards, with probability of marked card as parameter. Io value of blank cards was always zero.

differed significantly from zero by t-tests (two tails), with $\mathrm{p}<.05$. Neither sex difference was significant $(p>.10)$. Note that the mean difference scores obtained with exclusion of the extreme values of IO are based upon two positive and two negative values of 10 , instead of three of each, and are therefore smaller than those based upon all values of IO.

These results with probabilistic IO are similar to those of a comparable experiment by Irwin \& Snodgrass (1966) with IO that involved no uncertainty. The per- centages of Ss with positive, zero, and negative difference scores were 70,12 , and 18 in the present experiment (extreme IO's excluded) and 62.5, 15, and $22.5(\mathrm{~N}=120)$ in the Irwin-Snodgrass experiment. The two sets of frequencies upon which these percentages were based did not differ significantly by a chi-square test $(p>.5)$. Furthermore, the curves of Fig. 1 of the present experiment do not differ strikingly or systematically from those obtained in the earlier experiment. It may be concluded that, over the range of conditions of the two experiments, certain and uncertain values of IO have similar effects upon predictions of events that have these values.

\section{References}

Irwin, F. W., \& Snodgrass, J. G. Effects of independent and dependent outcome values upon bets. J. exp. Psychol., 1966, 7I, 282-285.

Marks, R. The effect of probability, desirability, and "privilege" upon the stated expectations of children. J. Pers., 1951, 19 332-351.

Morlock, H. D., Jr., \& Hertz, K. J. Effect of the desirability of outcomes on decision-making. Psychol. Rep., 1964, 14, 11-17.

Pruitt, D. G., \& Hoge, R. D. Strength of the relationship between the value of an event and its subjective probability as afunction of method of measurement. J. exp. Psychol., 1965, 69, 483-489.

\section{Note}

1. This investigation was supported by Research Grant MH-06580 from the National Institute of Mental Health to the University of Pennsylvania. 